\title{
Argon laser peripheral iridoplasty versus systemic intraocular pressure-lowering medications as immediate management for acute phacomorphic angle closure
}

\author{
This article was published in the following Dove Press journal: \\ Clinical Ophthalmology \\ 8 January 2013 \\ Number of times this article has been viewed
}

Jacky WY Lee'

Jimmy SM Lai'

Doris WF Yick ${ }^{2}$

Can YF Yuen ${ }^{2}$

'Department of Ophthalmology, University of Hong Kong,

${ }^{2}$ Department of Ophthalmology,

The Caritas Medical Centre, Kowloon

West Cluster, Hong Kong, People's

Republic of China
Correspondence: Jacky WY Lee Department of Ophthalmology, University of Hong Kong, Hong Kong, Room 30I, Level 3 Block B, Cyberport 4, 100 Cyberport

Road, Hong Kong, People's

Republic of China

Tel +852 3962 I406

Fax +852 28I74357

Email jackywylee@gmail.com
Background: The purpose of this study was to compare the efficacy and safety of argon laser peripheral iridoplasty (ALPI) and systemic intraocular pressure (IOP)-lowering medications in the immediate management of acute phacomorphic angle closure.

Methods: Consecutive cases of acute phacomorphic angle closure were randomized to receive ALPI and an intravenous or oral carbonic anhydrase inhibitor as initial treatment. Intravenous mannitol was administered for presenting IOP $>60 \mathrm{mmHg}$ or IOP $>40 \mathrm{mmHg} 2$ hours posttreatment in both arms.

Results: Of 10 consecutive cases, six received medical therapy and four received ALPI. Fifty percent in the medical group and none in the ALPI group required intravenous mannitol. The ALPI group took less time to achieve IOP $<25 \mathrm{mmHg}(18.8 \pm 7.5$ minutes versus $115.0 \pm 97.0$ minutes, $P=0.001, \mathrm{~F}$ test); had a greater IOP reduction within 30 minutes $(69.8 \% \pm 7.7 \%$ versus $40.9 \pm 23.9 \%, P=0.03, t$-test $)$; and had a consistently smaller post-attack cup to disc ratio $(0.50 \pm 0.02$ versus $0.60 \pm 0.20, P=0.002, \mathrm{~F}$ test $)$.

Conclusion: ALPI offers greater safety, consistency, and efficacy than systemic IOP-lowering medications as initial treatment for phacomorphic angle closure.

Keywords: phacomorphic, glaucoma, argon laser peripheral iridoplasty, medical, intraocular pressure

\section{Introduction}

Acute phacomorphic angle closure is a secondary angle closure resulting from a rapid increase in the anterior-posterior diameter of a mature cataract. This causes closure of the drainage angle and an acute elevation of intraocular pressure (IOP). ${ }^{1}$ Treatment includes lowering the IOP with medications and removing the cause by cataract extraction. ${ }^{1}$ Urgent treatment is important because persistent high IOP can result in permanent closure of the angle as well as irreversible optic nerve damage. ${ }^{2-4}$

Conventional medical treatment includes use of a systemic carbonic anhydrase inhibitor or a hyperosmolar agent, together with topical cycloplegic and antiglaucoma eye drops. Systemic carbonic anhydrase inhibitors are known to have many side effects, including metabolic acidosis, Stevens-Johnson syndrome, and blood dyscrasias. ${ }^{5-9}$ Systemic hyperosmotic agents can cause electrolyte disturbances, pulmonary edema, and congestive heart failure. ${ }^{10}$

However, medical treatment may fail to control IOP, and definitive treatment by cataract extraction can be risky in the acute phase because of corneal edema and 
elevated IOP. Recently, argon laser peripheral iridoplasty (ALPI) has been used to open up the angle in acute primary angle closure by placing a ring of laser burns on the peripheral iris to contract the iris stroma near the angle. This will open up the angle, thus lowering the IOP and allowing the eye to become quiet before definitive cataract extraction is performed. The usual practice is to perform ALPI 3-6 hours after maximal medications fail to control the IOP ${ }^{11-13}$ In acute primary angle closure, previous studies have demonstrated ALPI to be an effective and safe immediate treatment, avoiding the use of systemic IOP-lowering medications altogether. ${ }^{14-17}$ ALPI may work as effectively in acute phacomorphic angle closure.

The current practice of attempting maximal systemic antiglaucomatous treatments first may not be optimal, because those who fail to respond to medical treatment will have prolonged nerve damage from the persistent high IOP, and elderly patients may not be able to tolerate the side effects of the systemic carbonic anhydrase inhibitor and hyperosmotic agent. On the other hand, ALPI may be able to lower the IOP within a shorter time by mechanically opening up the drainage channels. The potential downsides include inflammation with high powers, possible synechial closure, and technical difficulties and inadvertent corneal damage in a shallow anterior chamber.

The objective of this study was to investigate whether or not ALPI is superior to traditional systemic antiglaucomatous medications in the immediate management of phacomorphic angle closure.

\section{Materials and methods}

This was a prospective, randomized, controlled study conducted at a district hospital in Hong Kong Special Administrative Region, People's Republic of China. Consecutive cases of acute phacomorphic angle closure were recruited from December 2009 to December 2010.

Acute phacomorphic angle closure was diagnosed by the presence of an intumescent cataract and signs of acute angle closure, including conjunctival injection, shallow anterior chamber, corneal edema in the index eye, and/or an open angle in the contralateral eye as determined by gonioscopy. The study received approval from the ethics committee of the hospital authority and followed the Declaration of Helsinki. There was no proprietary interest in the study.

Inclusion criteria were age $\geq 18$ years and ability to give informed consent, first acute attack of phacomorphic angle closure, and IOP $>40 \mathrm{mmHg}$. Exclusion criteria were IOP-lowering treatment received prior to the study, corneal opacity preventing laser treatment to the peripheral iris, and an uncooperative patient.

Snellen best corrected visual acuity (BCVA), duration of symptoms, gonioscopy, and IOP were recorded at baseline. All patients received one drop of atropine 1\% eye drops (Alcon Inc, Hünenberg, Switzerland) and one drop of timolol $0.5 \%$ eye drops (Santen Pharmaceutical Co, Ltd, Osaka, Japan) immediately after the diagnosis was made. The patients were randomized into two groups by an independent party, whereby the ALPI group received immediate ALPI and the medical group received systemic IOP-lowering medication. All treatments were delivered within one hour of presentation. In each group, if IOP was $>60 \mathrm{mmHg}$ on presentation, $200 \mathrm{~mL}$ of $20 \%$ intravenous mannitol was administered over one hour under cardiac monitoring. All IOPs were measured with Goldman applanation tonometry by a single investigator.

The ALPI group received ALPI under topical anesthesia with amethocaine 1\% (Alcon Inc, Hünenberg, Switzerland). The laser beam was focused onto the peripheral iris as close to the limbus as possible, using an Abraham contact lens. All four quadrants $\left(360^{\circ}\right)$ were treated. The laser energy was titrated until the end point was reached when localized iris contraction under area of treatment was visible.

The medical group received $500 \mathrm{mg}$ of intravenous acetazolamide. These patients continued to take acetazolamide $250 \mathrm{mg}$ four times daily and Slow-K ${ }^{\circledR}$ (Novartis, East Hanover, NJ) $600 \mathrm{mg}$ twice daily orally until IOP was normalized. Unlike in acute primary angle closure, laser peripheral iridotomy is not routinely performed for phacomorphic angle closure at our center because the aim of phacomorphic angle closure is to remove the intumescent cataract as soon as possible after achieving reasonable corneal clarity. Laser peripheral iridotomy may induce greater inflammation and cause zonular loosening, both delaying and making the cataract extraction more difficult.

After commencement of treatment, the IOP was measured at 15 minutes, 30 minutes, one hour, and hourly until it was below $25 \mathrm{mmHg}$, and measured on day 1 posttreatment. In each group, if the IOP remained $>40 \mathrm{mmHg}$ at 2 hours, $200 \mathrm{~mL}$ of $20 \%$ intravenous mannitol would be administered over one hour, if not already given. The ALPI group would also receive oral acetazolamide $250 \mathrm{mg}$ four times daily and Slow-K $600 \mathrm{mg}$ twice daily if the above conditions were met.

In both groups, the treated eye was maintained on $1 \%$ atropine daily, timolol $0.5 \%$ twice daily, and Pred Forte $1 \%$ 4-6 times per day (Allergan Inc, Irvine, CA) until definitive 
cataract extraction was performed by one of the three glaucoma surgeons at our center. Atropine is given to relieve the pupil block caused by anterior bulging of the intumescent cataract and to facilitate cataract extraction later on.

Definitive treatment with cataract extraction and intraocular lens insertion was performed within 72 hours after IOP control. Specular microscopy was performed for both eyes of each patient at 3 months after the attack. BCVA was measured one month after cataract extraction. Gonioscopy and ultrasound biomicroscopy (Paradigm Medical Industries Inc, Salt Lake City, UT) were performed at 3 months post attack. Stratus optical coherence tomography (Carl Zeiss Meditec Inc, Dublin, CA) was used for retinal nerve fiber layer and optic nerve head analyses at 3 and 9 months post attack.

During the preliminary outcome assessment, the investigators decided to terminate the study prematurely as a result of the clinically significant differences in outcome between the two treatment groups and the disproportionate number of subjects requiring intravenous mannitol in the medical group.

Statistical comparisons between the ALPI and medical group were performed using a $t$-test with Welch correction. Given the limitation in sample size as a result of early termination of the study, we anticipated that statistical significance may not be apparent, so we also supplemented our analysis with the $\mathrm{F}$ test for unequal variance. A statistically significant F test would also be able to validate that the two populations had different outcomes from the two treatments. All means were expressed as the mean \pm standard deviation. Statistical significance was defined as $P<0.05$.

\section{Results}

Ten consecutive cases were included in the study. All patients were of Chinese ethnicity. Six cases (two male and four female) received medical therapy (three right eyes and three left eyes). Four cases (one male and three female) received ALPI (one right eye and three left eyes). The mean patient age was $79.7 \pm 7.2$ years in the medical group and $78.3 \pm 11.0$ years in the ALPI group. The mean presenting IOP was $50.7 \pm 8.4 \mathrm{mmHg}$ in the medical group and $50.3 \pm 6.9 \mathrm{mmHg}$ in the ALPI group. The mean duration of the attack was $2.8 \pm 3.5$ days in the medical group and $0.9 \pm 0.25$ days in the ALPI group based on the history of symptom duration. For the presenting BCVA, the medical group had three cases with hand movement and three with light perception, whilst the ALPI group had one case with hand movement and three cases with light perception.

In the medical group, 50\% (3/6) required intravenous mannitol, due to one case presenting with IOP $>60 \mathrm{mmHg}$ and two cases of IOP $>40 \mathrm{mmHg}$ after 2 hours of treatment with the systemic carbonic anhydrase inhibitor. There were no serious adverse effects from the systemic IOP-lowering medications. None of the cases in the ALPI group required intravenous mannitol. All ALPI procedures were performed by a single surgeon within 5-10 minutes in the manner described above, with a mean of $54.5 \pm 14.8$ laser shots. There were no complications from ALPI.

Fifteen minutes after treatment, the mean IOP reduction from presentation in the medical group was $20.0 \pm 14.0 \mathrm{mmHg}$ $(40.0 \% \pm 27.4 \%)$ and $33.8 \pm 10.9 \mathrm{mmHg}(67.7 \% \pm 20.9 \%)$ in the ALPI group. At 30 minutes, the mean IOP reduction was $20.8 \pm 5.5 \mathrm{mmHg}(40.9 \% \pm 23.9 \%)$ in the medical group and $34.8 \pm 1.6 \mathrm{mmHg}(69.8 \% \pm 7.7 \%)$ in the ALPI group. At one hour, the mean IOP reduction was $15.5 \pm 24.0 \mathrm{mmHg}$ $(37.0 \% \pm 31.6 \%)$ in the medical group and $34.7 \pm 3.2 \mathrm{mmHg}$ $(64.5 \% \pm 4.3 \%)$ in the ALPI group. At 2 hours, the mean IOP reduction was $24.3 \pm 17.4 \mathrm{mmHg}(46.4 \% \pm 29.1 \%)$ in the medical group and $31.7 \pm 4.0 \mathrm{mmHg}(66.0 \% \pm 11.8 \%)$ in the ALPI group. At day 1 posttreatment, the mean IOP reduction was $33.7 \pm 8.2 \mathrm{mmHg}(68.7 \% \pm 6.6 \%)$ in the medical group and $33.5 \% \pm 9.6 \% \mathrm{mmHg}(66.8 \% \pm 16.5 \%)$ in the ALPI group. All eyes in the ALPI group had IOP $<25 \mathrm{mmHg}$ within 30 minutes of treatment (see Figure 1).

The mean time taken to reduce the presenting IOP to $<25 \mathrm{mmHg}$ was $115.0 \pm 97.0$ minutes in the medical group and $18.8 \pm 7.5$ minutes in the ALPI group ( $t$-test $P=0.06$, F test $P=0.001$, see Figure 2) The mean percentage of IOP reduction from presentation in the ALPI group $(69.8 \% \pm 7.7 \%)$ was significantly greater than in the medical group $(40.9 \% \pm 23.9 \%)$ at 30 minutes posttreatment ( $t$-test $P=0.03$, F test $P=0.09$, see Figure 3).

One day after treatment, all cases in each group achieved a clear cornea and IOP $<21 \mathrm{mmHg}$ in the medical group (on oral acteazolamide and timolol $0.5 \%$ ) and with a mean IOP of $15.8 \pm 4.2 \mathrm{mmHg}$ in the medical group and $16.7 \pm 9.0 \mathrm{mmHg}$ in the ALPI group (on timolol $0.5 \%$ alone) ( $t$-test $P=0.9, \mathrm{~F}$ test $P=0.1$ ). The medical group had cataract extraction done at a mean of $1.7 \pm 0.8$ days after the initial treatment and the ALPI group had cataract extraction done $1.3 \pm 0.5$ days after the initial treatment.

All cases in both groups received extracapsular cataract extraction and intraocular lens without any intraoperative complications, but one case from the medical group required a scleral fixation intraocular lens due to lens subluxation one week postoperatively. There was no documented trauma history.

The postoperative mean BCVA was $0.4 \pm 0.2$ in both groups. At 3 months, the IOP without medication for the 


\section{Treatment duration (minutes)}

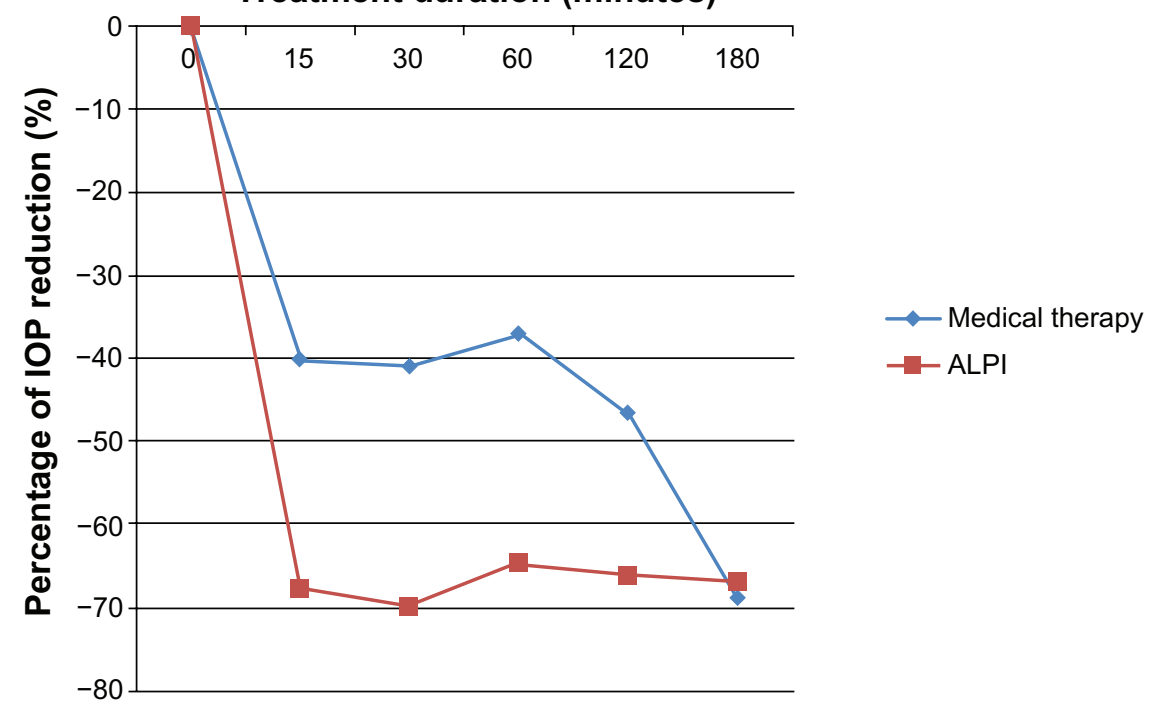

Figure I Percentage of IOP reduction following treatment.

Abbreviations: ALPI, argon laser peripheral iridoplasty; IOP, intraocular pressure.

medical group was 11.2 $\pm 4.2 \mathrm{mmHg}$ and $9.5 \pm 2.3 \mathrm{mmHg}$ for the ALPI group ( $t$-test $P=0.4$, F test $P=0.4$ ). At 9 months, the mean IOP was $11.2 \pm 3.3 \mathrm{mmHg}$ in the medical group and $11.5 \pm 3.1 \mathrm{mmHg}$ in the ALPI group (t test $P=0.7, \mathrm{~F}$ test $P=1.0$ ). One case in the medical group required topical antiglaucoma medication to maintain IOP $<21 \mathrm{mmHg}$.

The mean degree of peripheral anterior synechiae formation at 3 months was $45.0^{\circ} \pm 45.3^{\circ}$ and $22.5^{\circ} \pm 45.0^{\circ}$ in the medical group and ALPI group, respectively ( $t$-test $P=0.5, \mathrm{~F}$ test $P=1.0$ ). The mean trabecular-iris angle by ultrasound biomicroscopy was $35.9^{\circ} \pm 4.6^{\circ}$ and $38.8^{\circ} \pm 3.6^{\circ}$ in the medical group and ALPI group, respectively ( $t$-test $P=0.2, \mathrm{~F}$ test $P=0.9$ ).

The mean endothelial cell count for the medical group was $1928.5 \pm 529.1$ cells $/ \mathrm{mm}^{2}$ at 3 months and

\section{Time to IOP $<25 \mathrm{mmHg}$}

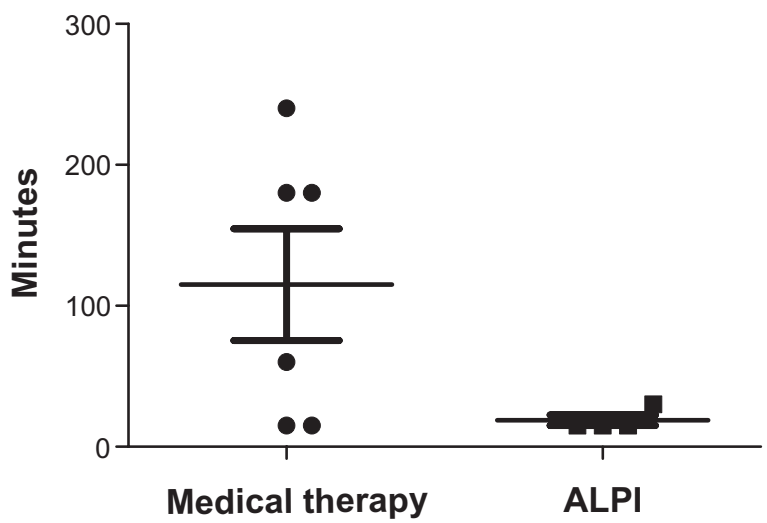

Figure 2 Time taken to lower IOP to $<25 \mathrm{mmHg}$. Abbreviations: ALPI, argon laser peripheral iridoplasty; IOP, intraocular pressure.
$2318.2 \pm 887.7$ cells $/ \mathrm{mm}^{2}$ in the uninvolved contralateral eye. In the ALPI group, the mean endothelial cell count was $2379.3 \pm 573.3$ cells $/ \mathrm{mm}^{2}$ and $2509 \pm 694.6$ cells $/ \mathrm{mm}^{2}$ in the contralateral eye. There was no significant difference between the two groups ( $t$-test $P=0.3$, F test $P=0.8$ ).

Mean retinal nerve fiber layer thickness for the medical group was $88.7 \pm 21.6 \mu \mathrm{m}$ at 3 months and $78.3 \pm 20.5 \mu \mathrm{m}$ at 9 months. Mean retinal nerve fiber layer thickness in the contralateral eye of the medical group measured at 3 months was $101.0 \pm 22.3 \mu \mathrm{m}$. For the ALPI group, mean retinal nerve fiber layer thickness layer was $102.9 \pm 24.4 \mu \mathrm{m}$ at 3 months and $96.1 \pm 19.1 \mu \mathrm{m}$ at 9 months. Mean retinal nerve fiber layer thickness in the contralateral eye was $105.0 \pm 20.0 \mu \mathrm{m}$ when measured at 3 months. There were no significant differences in retinal nerve fiber layer thickness between the

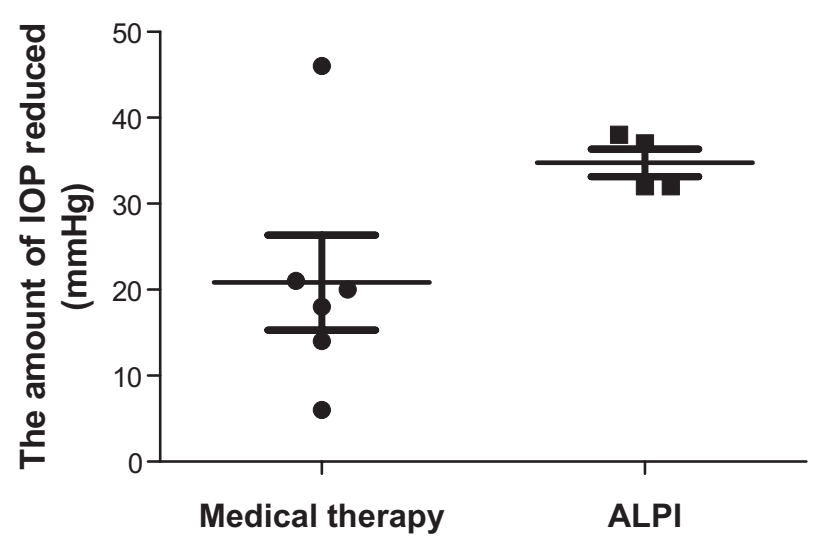

Figure 3 Amount of IOP reduction within the first 30 minutes of treatment. Abbreviations: ALPI, argon laser peripheral iridoplasty; IOP, intraocular pressure. 
Table I Comparison between medical therapy versus ALPI

\begin{tabular}{|c|c|c|}
\hline & Medical therapy $(n=6)$ & $\operatorname{ALPI}(n=4)$ \\
\hline Mean age & $79.7 \pm 7.2$ years & $78.3 \pm 11.0$ years \\
\hline Mean presenting IOP & $50.7 \pm 8.4 \mathrm{mmHg}$ & $50.25 \pm 6.9 \mathrm{mmHg}$ \\
\hline Presenting VA & $\mathrm{HM}$ to LP & HM to LP \\
\hline Mean duration of phacomorphic angle closure & $2.8 \pm 3.5$ days & $0.9 \pm 0.25$ days \\
\hline Mean percentage reduction of IOP I5 mins after treatment & $40.0 \% \pm 27.4 \%$ & $67.7 \% \pm 20.9 \%$ \\
\hline Mean percentage reduction IOP 30 mins after treatment & $40.9 \% \pm 23.9 \%$ & $69.8 \% \pm 7.7 \%$ \\
\hline Mean percentage reduction IOP 60 mins after treatment & $37.0 \% \pm 31.6 \%$ & $64.5 \% \pm 4.3 \%$ \\
\hline Mean percentage reduction IOP I 20 mins after treatment & $46.4 \% \pm 29.1 \%$ & $66.0 \% \pm 11.8 \%$ \\
\hline Mean percentage reduction IOP I day after treatment & $68.7 \% \pm 6.6 \%$ & $66.8 \% \pm 16.5 \%$ \\
\hline Mean IOP at Day I after treatment & $15.8 \pm 4.2 \mathrm{mmHg}$ & $16.7 \pm 9.0 \mathrm{mmHg}$ \\
\hline Percent requiring IV mannitol & $50 \%$ & 0 \\
\hline Mean time from treatment to cataract extraction & $1.7 \pm 0.8$ days & $1.3 \pm 0.5$ days \\
\hline Mean IOP at 3 months after attack & $1 \mathrm{I} .2 \pm 4.2$ & $9.5 \pm 2.3 \mathrm{mHg}$ \\
\hline Mean IOP at 9 months after attack & $11.2 \pm 3.3 \mathrm{mmHg}$ & $1 \mathrm{I} .5 \pm 3.1 \mathrm{mmHg}$ \\
\hline Precent requiring topical glaucoma medication & $16.7 \%$ & 0 \\
\hline Mean BCVA at I month after attack & $0.4 \pm 0.2$ & $0.4 \pm 0.2$ \\
\hline Mean angle at 3 months after attack & $35.9^{\circ} \pm 4.6^{\circ}$ & $38.8^{\circ} \pm 3.6^{\circ}$ \\
\hline Mean PAS at 3 months after attack & $45.0^{\circ} \pm 45.3^{\circ}$ & $22.5^{\circ} \pm 45.0^{\circ}$ \\
\hline \multirow[t]{2}{*}{ Mean endothelial count at 3 months after attack } & $1928.5 \pm 529.1$ & $2379.3 \pm 573.3$ \\
\hline & cells $/ \mathrm{mm}^{2}$ & cells $/ \mathrm{mm}^{2}$ \\
\hline Mean RNFL at 3 months after attack & $88.7 \pm 21.6$ um & $102.9 \pm 24.4$ um \\
\hline Mean RNFL at 9 months after attack & $78.3 \pm 20.5$ um & $96.1 \pm 19.1$ um \\
\hline Mean CDR by OCT 3 months after attack & $0.6 \pm 0.2$ & $0.5 \pm 0.02$ \\
\hline
\end{tabular}

Abbreviations: ALPI, argon laser peripheral iridoplasty; BCVA, best-corrected visual acuity; CDR, cup-to-disc ratio; HM, hand movement; LP, light perception; OCT, optical coherence tomography; RNFL, retinal nerve fiber layer; PAS, peripheral anterior synechiae; IV, intravenous; IOP, intraocular pressure; VA, visual acuity.

two treatment arms at either 3 or 9 months $(t$-test $P>0.2$, F test $P>0.8$ ). The 3 -month mean cup to disc ratio by optical coherence tomography analysis of the optic nerve head was $0.60 \pm 0.20$ and $0.50 \pm 0.02$ in the medical group and ALPI group, respectively ( $t$-test $P=0.2, \mathrm{~F}$ test $=0.002$, see Table 1).

\section{Discussion}

Tham et al have established ALPI to be effective in IOP-lowering for phacomorphic angle closure, reducing the IOP by $19.3 \%$ in the first 15 minutes, with the only contraindications being poor endothelial function and eyes with flat anterior chambers. ${ }^{16}$ The question that remains unanswered is how does ALPI compare with traditional systemic medical therapy?

In our study comparing the safety and efficacy of medical therapy versus ALPI, both groups had similar presenting IOP of $>50 \mathrm{mmHg}$, but the amount and rate of IOP decrease was more pronounced in the ALPI group.

The mean time taken to reduce the presenting IOP to $<25 \mathrm{mmHg}$ was 115 (range 15-240) minutes when using systemic medication, but only 19 (range 15-30) minutes when using ALPI alone. Within the first 30 minutes, there was a significantly greater IOP reduction in the ALPI group
(69\%, IOP reduction range $32-38 \mathrm{mmHg}$ ) compared with the medical group (41\%, IOP reduction range 6-46 $\mathrm{mmHg})$. Thus, ALPI not only offered close to $30 \%$ more IOP reduction compared with medical therapy within just 30 minutes of treatment, but produced more consistent results with less variability. In addition, the mean IOP reduction at all time points on treatment day was greater in the ALPI group. Even one day after treatment, the ALPI group was able to sustain an IOP reduction of $67 \%$, similar to that in patients in the medical group who were receiving oral acetazolamide. Thus, ALPI may be able to replace the use of systemic acetazolamide in phacomorphic angle closure.

In terms of safety, $50 \%$ of those receiving intravenous and oral carbonic anhydrase inhibitors eventually required intravenous mannitol to lower their IOP further. As a precaution, all intravenous mannitol was given under continuous cardiac monitoring. Although no serious systemic complications were noted from the systemic medications, hyperosmolar agents may not be suitable for all elderly patients, especially those with pre-existing renal impairment, pulmonary edema, or congestive heart failure. None of the ALPI-treated patients required supplementary intravenous mannitol. There were no side effects from the ALPI, apart from faint laser marks on the peripheral iris, visible only on slit-lamp examination. 
Both groups achieved a normalized IOP and clear cornea to allow for uneventful cataract extractions within 1-2 days of presentation.

Postoperatively, one case in the medical group required scleral fixation of an intraocular lens due to subluxation one week postoperatively. This lens subluxation was likely to be due to zonular loosening because there was no history of trauma postoperatively. The mean BCVA was 0.4 in both groups.

Both groups had open angles at 3 months via gonioscopy and ultrasound biomicroscopy, but the ALPI group had 50\% less peripheral anterior synechiae formation as compared with the medical group, possibly due to prompter angle opening during the laser-induced contractions of the peripheral iris. The postoperative IOP at 3 and 9 months was comparable, with a mean difference of less than $2 \mathrm{mmHg}$ in both treatment arms. Only one case belonging to the medical group required topical glaucoma medication to maintain IOP $<21 \mathrm{mmHg}$.

In both groups, the post-attack endothelial cell count was lower compared with that in the uninvolved eye, which can be used as a proxy measure of the pre-attack state for each individual. We were unable to obtain any pre-attack endothelial cell counts because all cases presented only during phacomorphic attack. The mean endothelial count in the medical group (1928 cells $/ \mathrm{mm}^{2}$ ) was slightly lower than that in the ALPI group (2379 cells $/ \mathrm{mm}^{2}$ ).

The majority of the patients in this study were unable to produce reliable Humphrey visual field assessments. Using optical coherence tomography for assessment of the optic nerve head, we found a smaller mean cup to disc ratio of 0.5 (range $0.47-0.50$ ) in the ALPI group and 0.6 (range $0.39-0.94$ ) in the medical group, with much greater variability in the medical group. Both treatment arms had a thinner mean retinal nerve fiber layer as compared with the contralateral eye, which can be used as a proxy measure of the pre-attack state. However, in the medical group, the mean retinal nerve fiber layer seemed to be thinner compared with that in the ALPI group at both 3 and 9 months following the attack.

Our study had a limited sample size due to its early termination for safety and ethical reasons. Due to the dramatic difference in time taken to lower the presenting IOP to $<25 \mathrm{mmHg}$ (115 minutes in the medical group versus 19 minutes in the ALPI group), the percentage of patients requiring intravenous mannitol $(50 \%$ in the medical group versus $0 \%$ in the ALPI group), and the amount of IOP lowering within 30 minutes of treatment (41\% in medical group versus $69 \%$ in the ALPI group), the investigators concluded that it would be unethical to continue this study just to achieve a greater statistical significance in data whilst subjecting patients to a slower IOP reduction and the unnecessary adverse effects of systemic medical therapy. Although we were just short of demonstrating a statistically significant difference in the mean time taken to lower IOP to $<25 \mathrm{mmHg}$ $(P=0.06, t$-test $)$, the finding of a statistically significant difference in variance ( $P=0.001, \mathrm{~F}$ test) was just as important in validating a difference in outcome between the two treatment arms. Similarly, a difference of 0.1 in the cup to disc ratio detected on optical coherence tomography may not be of much clinical significance, but what the difference in variance signifies is that ALPI delivered more consistency in achieving a lower cup to disc ratio overall compared with the medical group, in which the post-attack cup to disc ratio outcome was more variable. We postulate that the individual physiological response to systemic medication can vary. Whilst some patients respond rapidly, others may take longer, giving rise to greater variability in IOP lowering and less predictable glaucomatous optic nerve damage, as reflected by a more variable cup to disc ratio post attack. However, for ALPI, the effect is primarily mechanical, hence the response and outcome is not only rapid but consistent for all treated patients in terms of degree of IOP reduction, time taken to normalize IOP, and post-attack cup to disc ratio.

There was a slight difference in presentation time between the medical group (2 days) and the ALPI group (one day). However, given that the treatment was randomized and previous studies have documented good outcomes for presentations less than 5 days, ${ }^{17}$ this minor difference in presentation is negligible because the presenting IOP in both treatment arms was similar and both groups were able to achieve normalization of IOP and corneal clarity one day posttreatment.

To the best of our knowledge, this is the first trial directly comparing ALPI versus conventional systemic medication for the immediate management of phacomorphic angle closure. The advantages of ALPI are that it: generates a more consistent, rapid, and greater reduction of IOP to $<25 \mathrm{mmHg}$ within 30 minutes of treatment; avoids use of systemic carbonic anhydrase inhibitors and hyperosmotic agents; produces a consistently smaller cup to disc ratio post attack; and achieves a comparable post-attack visual acuity, endothelial cell count, angle status, retinal nerve fiber layer thickness, and IOP when compared with medical therapy. Immediate ALPI may be utilized in phacomorphic angle closure as a safer, more rapid, and more consistent modality of IOP reduction in place of systemic IOP-lowering medications. 


\section{Disclosure}

The authors report no conflicts of interest in this work, which was presented in part at the European Glaucoma Society conference in June 2012, Copenhagen, Denmark and the Asia Pacific Glaucoma Congress in December 2012, Bali, Indonesia.

\section{References}

1. Leibmann JM, Ritch R. Glaucoma associated with lens intumescence and dislocation. In: Ritch R, Shields MB, Krupin T, editors. The Glaucomas, 2nd ed. St Louis, MO: Mosby; 1996.

2. David R, Tessler Z, Yassur Y. Long term outcome of primary acute angle closure glaucoma. Br J Ophthalmol. 1993;17:33-36.

3. Kanellopoulos AJ, Perry HD, Donnenfeld ED. Comparison of topical timolol gel to oral acetazolamide in the prophylaxis of viscoelasticinduced ocular hypertension after penetrating keratoplasty. Cornea. 1997; 16:12-15.

4. Hart WM, Becker B. The onset and evolution of glaucomatous visual field defect. Ophthalmology. 1982;89:991-998.

5. Berson FG, Ebstein DL. Carbonic anhydrase inhibitors: management of side effects. Perspect Ophthalmol. 1980;4:91-96.

6. Cowan RA, Hartnell GG, Lowdell CP, Baird IM, Leak AM. Metabolic acidosis induced by carbonic anhydrase inhibitor and salicylates in patients with normal renal function. $\mathrm{Br} \mathrm{Med} J$. (Clin Res $\mathrm{Ed}$ ). 1984;289:347-348.
7. Mogk K, Cyrlin MN. Blood dyscrasias and carbonic anhydrase inhibitors Ophthalmology. 1988;95:768-771.

8. Shirato S, Kagaya F, Suzuki Y, et al. Stevens Johnson syndrome induced by methazolamide treatment. Arch Ophthalmol. 1997;115:550-553.

9. Chaparon DJ, Gomolin IH, Sweeney KR. Acetazolamide blood concentrations are excessive in the elderly: propensity for acidosis and relationship to renal function. J Clin Pharmacol. 1989;29:348-353.

10. D'Alena P, Ferguson W. Adverse effects after glycerol orally and mannitol parentally. Arch Ophthalmol. 1966;75:201-203.

11. Ritch R. Argon laser treatment for medically unresponsive attacks of angle-closure glaucoma. Am J Ophthalmol. 1982;94:197-204.

12. Lim ASM, Tan A, Chew P, et al. Laser iridoplasty in the treatment of severe acute angle closure glaucoma. Int Ophthalmol. 1993;17:33-36.

13. Sassani JW, Ritch R, McCormick S. Histopathology of argon laser peripheral iridoplasty. Ophthalmic Surg. 1993;24:740-745.

14. Lam DS, Lai JS, Tham CC. Immediate argon laser peripheral iridoplasty (ALPI) as treatment for acute attack of primary angle closure glaucoma: a preliminary study. Ophthalmology. 1998;105:2231-2236.

15. Lai JS, Tham CC, Lam DS. Limited argon laser peripheral iridoplasty as immediate treatment for an acute attack of primary angle closure glaucoma: a preliminary study. Eye. 1999;13:26-30.

16. Tham CC, Lai JS, Lam DS. Immediate argon laser peripheral iridoplasty for acute attack of PACG. Ophthalmology. 1999;106:1042-1043.

17. Lee WY, Lai SM, Yick WF, Yuen YF. Prospective case series on retinal nerve fibre layer changes after an acute episode of phacomorphic angle closure. Int Ophthalmol. 2012;32:577-582.
Clinical Ophthalmology

\section{Publish your work in this journal}

Clinical Ophthalmology is an international, peer-reviewed journal covering all subspecialties within ophthalmology. Key topics include: Optometry; Visual science; Pharmacology and drug therapy in eye diseases; Basic Sciences; Primary and Secondary eye care; Patien Safety and Quality of Care Improvements. This journal is indexed on

Submit your manuscript here: http://www.dovepress.com/clinical-ophthalmology-journal

\section{Dovepress}

PubMed Central and CAS, and is the official journal of The Society of Clinical Ophthalmology (SCO). The manuscript management system is completely online and includes a very quick and fair peer-review system, which is all easy to use. Visit http://www.dovepress.com/ testimonials.php to read real quotes from published authors. 